\title{
Minimally invasive CT-guided excision of osteoid osteoma and other small benign bone tumours: a single centre case series in South Africa
}

\author{
Sluis Cremer $\mathrm{T}^{1} \mathbb{D}$, Hosking $\mathrm{K}^{2} \mathbb{0}$, Held $\mathrm{M}^{3} \mathbb{C}$, Hilton $\mathrm{TL}^{4}$ \\ MBChB(UCT), FCOrth(SA), MMed(UCT); Division of Orthopaedic Surgery, University of Cape Town and Groote Schuur Hospital, Cape Town, \\ South Africa \\ $2 \mathrm{MBChB}(\mathrm{UCT})$, FCOrth(SA); Cape Orthopaedic Reconstruction Unit, Life Vincent Pallotti Hospital, Pinelands, Cape Town, South Africa \\ $3 \mathrm{MD}(\mathrm{LMU}), \mathrm{PhD}(\mathrm{UCT})$, MMed(UCT)Ortho, FCOrth(SA); Division of Orthopaedic Surgery, University of Cape Town and Groote Schuur Hospital, \\ Cape Town, South Africa \\ $4 \mathrm{MBChB}(\mathrm{UCT}), \mathrm{DA}(\mathrm{SA})$, DipPEC(SA), MMed(UCT), FCOrth(SA); Division of Orthopaedic Surgery, University of Cape Town and Groote Schuur \\ Hospital, Cape Town; Cape Orthopaedic Reconstruction Unit, Life Vincent Pallotti Hospital, Pinelands, Cape Town, South Africa
}

Corresponding author: Dr T Sluis Cremer, Division of Orthopaedic Surgery, Groote Schuur Hospital, H49 OMB, Observatory, South Africa; tel: 021404 5118; email: timsluis@gmail.com

\begin{abstract}
Background: The management of osteoid osteoma $(\mathrm{OO})$ and other small primary benign lesions of bone has evolved over the past 50 years from open surgery with wide resection margins to less invasive surgical techniques such as image-guided intralesional excision and percutaneous radiofrequency ablation. We aim to evaluate the outcomes of patients treated with computerised tomography (CTguided) intralesional excision and bone grafting of small benign lesions of bone.

Method: A retrospective folder review of patients treated in a large academic hospital in Cape Town, South Africa, between March 2012 and May 2016 was performed. Patient demographics, details of presentation, clinical information and outcome following treatment were analysed descriptively. Pre-operative diagnosis based on radiological examination was compared with histological diagnosis.

Result: Eleven patients (five male) with a median age of 16 years (range 5-33) were included. Pain was the most common presenting feature. A histological diagnosis of $\mathrm{OO}$ was confirmed in five of nine patients with a suspected diagnosis of OO pre-operatively. Of the four patients whose diagnosis changed after the procedure, the diagnoses included a benign spindle cell lesion, a benign fibrous histiocytoma, subacute osteitis and an osteochondral defect with geode cyst formation. Of the two patients where OO was not suspected pre-operatively, chondroblastoma was confirmed in one while a benign spindle cell lesion was reported in the other. Overall histological yield was thus $100 \%$. There were no complications or repeat procedures at a median follow-up of 42 months (range 30-52 months).

Conclusion: CT-guided intralesional curettage is a safe and minimally invasive technique. This is especially useful in less accessible regions of the skeleton as it provides a means of accurately locating the lesion with minimal risk of complications and morbidity to the patient. We consider this to be the optimal method of treatment in our setting as it provides high success rates, few complications and a histological diagnosis without the need for any additional and expensive equipment.
\end{abstract}

Level of evidence: Level 4

Key words: CT guidance, osteoid osteoma, percutaneous treatment, benign bone tumours, intralesional curettage, radiofrequency ablation

Citation: Sluis Cremer T, Hosking K, Held M, Hilton TL. Minimally invasive CT-guided excision of osteoid osteoma and other small benign bone tumours: a single centre case series in South Africa. SA Orthop J 2019;18(1):26-32. http://dx.doi.org/10.17159/2309-8309/2019/v18n1a3

Editor: Prof LC Marais, University of KwaZulu-Natal, Durban, South Africa

Received: April 2018

Accepted: July 2018

Published: March 2019

Copyright: (c) 2018 Sluis Cremer T, et al. This is an open-access article distributed under the terms of the Creative Commons Attribution Licence, which permits unrestricted use, distribution and reproduction in any medium, provided the original author and source are credited.

Funding: This research received no specific grant from any funding agency in the public, commercial, or not-for-profit sectors.

Conflict of interest: All named authors hereby declare that they have no conflicts of interest to disclose. 


\section{Introduction}

Osteoid osteoma $(\mathrm{OO})$ is one of the most important primary benign lesions of bone, due in part to the profound pain and disability it causes patients. It is also the most common, accounting for $12 \%$ of primary benign bone tumours. ${ }^{1}$ Its differential diagnosis includes osteoblastoma, chondroblastoma, enchondroma and chondromyxoid fibroma as well as traumatic conditions, such as stress fracture, or infection, in the case of a Brodie's abscess. ${ }^{2}$ The natural history of an $\mathrm{OO}$ is that of spontaneous resolution, and malignant transformation has never been described. ${ }^{3-6}$ Symptomatic relief can be gained with the regular use of nonsteroidal antiinflammatory drugs (NSAIDs) but side effects, particularly gastric irritation, may hamper this strategy. ${ }^{4-6}$ In refractory cases surgical excision is usually curative. ${ }^{7}$ This may be performed in a number of ways: either by open marginal excision or through less invasive techniques, performed under image guidance, such as direct curettage, laser photocoagulation and radiofrequency ablation with or without biopsy. ${ }^{8}$ Novel techniques such as magnetic resonanceguided focused ultrasound (MRgFUS) ${ }^{9-11}$ and arthroscopic excision are also currently being evaluated..$^{12-15}$

While the use of novel techniques to deal with small benign bone tumours is becoming ever more popular, the additional time and cost are not yet justified by better patient outcomes. ${ }^{16}$

At our centre, computer tomography (CT) guided percutaneous curettage and bone grafting is performed as this method has a high success rate, a low number of complications, and provides a histological diagnosis without the need for costly additional equipment. ${ }^{17}$

The aim of this study was to describe the surgical technique and determine the clinical outcomes of patients treated by CT-guided percutaneous curettage.

\section{Materials and methods}

Following institutional ethical approval (HREC REF: 670/2016) a retrospective folder review was performed. Included were all patients who underwent minimally invasive CT-guided intralesional excision of a primary benign bone tumour between March 2012 and May 2016. Excluded were extraosseous lesions, inadequate follow-up (less than one year), incomplete records and lesions that were malignant or located outside of bone. Patient demographics, details of presentation, clinical information and outcome following treatment were analysed. Pre-operative diagnosis based on radiological assessment was compared with histological diagnosis.

\section{Surgical technique and aftercare}

A senior surgeon performed the surgery in all cases at a single centre and all patients gave informed consent prior to surgery. Patients were admitted on the morning of surgery and discharged on the same day. Prophylactic cefazolin $1 \mathrm{~g}$, or clindamycin $600 \mathrm{mg}$ in the case of penicillin allergy, was administered. Anaesthesia was induced in theatre after which the patient was transferred to the radiology suite and positioned inside the $\mathrm{CT}$ scanner. The location of the lesion was accurately determined in the axial, sagittal and coronal planes. The entry point was planned and marked on the skin (such that the path of the wire would avoid major anatomical structures). A threaded tipped Kirschner wire (K-wire) was inserted percutaneously by a qualified radiologist under CT guidance, in a sterile manner, using an orthopaedic drill (Figures 1 and 2). The K-wire was then cut to within $3 \mathrm{~cm}$ of the skin and covered with a sterile dressing. The patient was then transferred back to theatre, where a full standard preparation and draping was performed. A small skin incision was made to allow a $6 \mathrm{~mm}$ cannulated drill bit

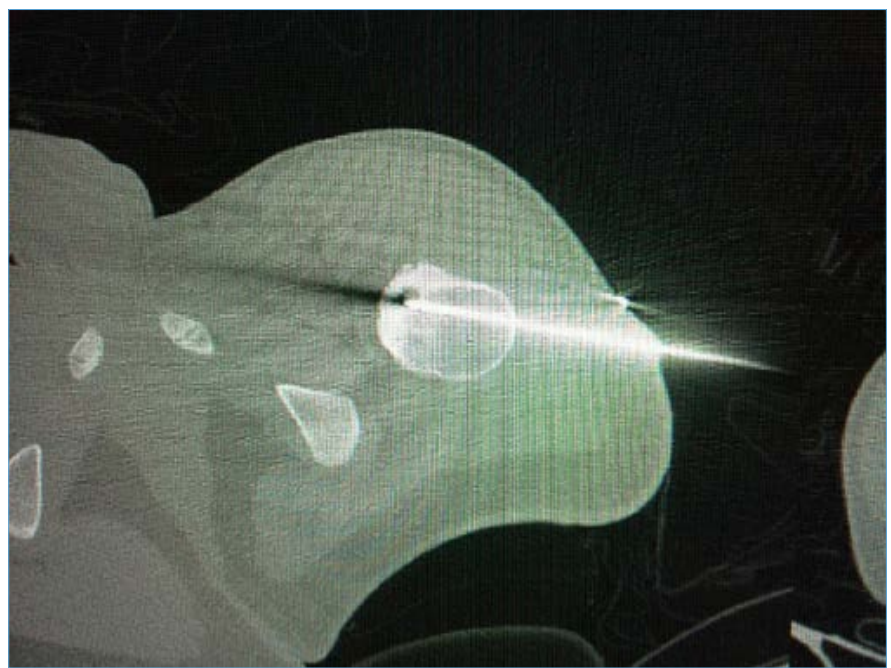

Figure 1. Axial view of a dynamic CT scan shows the K-wire tip located within the nidus of a proximal femur $\mathrm{OO}$

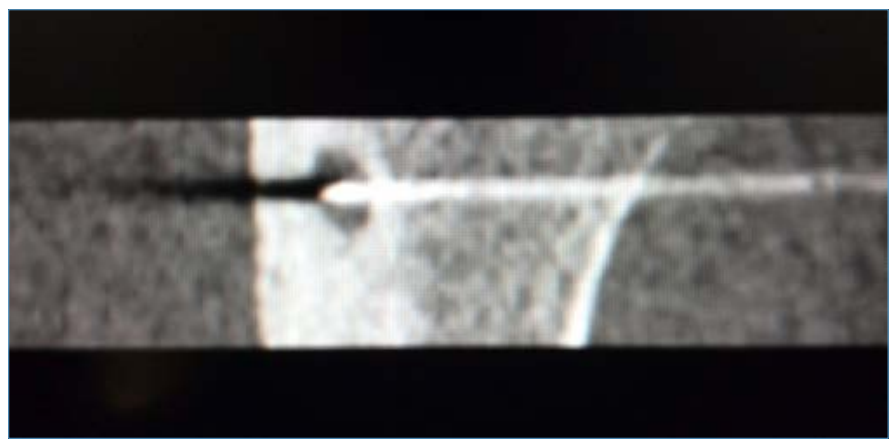

Figure 2. Magnified axial view of the same lesion as in Figure 4 with K-wire in situ

to be passed over the K-wire and drilled down into the lesion. The K-wire was lubricated with K-Y Jelly (Reckitt Benckiser, Berkshire, UK) to prevent it from spinning with the drill bit and inadvertently advancing beyond the lesion. A long-handled curette was passed down the drill hole (after removing the K-wire) and the contents of the lesion curetted and sent for histology and microbiological culture. Fluoroscopy was used to confirm the position of the K-wire and ensure adequacy of the curettage. Allomatrix (Wright Medical, Middlesex, UK) demineralised bone matrix (DBM) calcium sulphate putty was injected into the cavity and the incision closed in a standard fashion. Postoperatively patients with lower limb lesions were kept non-weight bearing on crutches for two weeks for comfort with graduated return to full weight bearing status at six weeks. No specific rehabilitation or weight bearing protocol was prescribed. Patients had X-rays (XR) postoperatively to assess recurrence and adequacy of healing.

\section{Statistical analysis}

Due to the small cohort identified, meaningful statistical analysis was not feasible. We therefore report on descriptive statistics only.

\section{Results}

All patients presented due to limb pain and had a delay to final diagnosis. A histological diagnosis was available in all cases and there were no complications or recurrence. Four of the nine patients with suspected $\mathrm{OO}$ had histological diagnosis of a different benign lesion. 


\section{Patients}

Thirteen patients were identified who had undergone CT-guided percutaneous excision of a primary bone lesion. Two patients were excluded. These included a biopsy of a metastatic renal cell carcinoma from within the muscles of the shoulder girdle and the other a biopsy of a retroperitoneal Schwannoma.

\section{Demographics}

Overall, there were five male patients and six female, with a median age 16 years (range 5-33). Of the five patients with an 00 , three were male, the median age of whom was 19 years (range 12-20).

\section{Symptoms at presentation}

Localised pain was the primary presenting complaint in all patients with a median duration of 6 months (range 1-26 months). In four of the $11(36 \%)$ patients, the pain was associated with a limp; seven of the $11(63 \%)$ complained of night pain; and three (27\%) had activity-related pain. Six (54\%) patients reported pain relief with NSAID use. All five of the patients with 00 complained of night pain and three of these reported transient relief of symptoms with NSAID use. One patient with a proximal tibia OO had mechanical knee symptoms including knee locking and an effusion. This patient had a delay in diagnosis of 26 months as meniscal pathology was suspected and the initial magnetic resonance image (MRI) failed to diagnose $\mathrm{OO}$. These symptoms resolved following excision of the OO. There was no difference in clinical presentation between patients with $\mathrm{OO}$ and those with other diagnoses.

\section{Imaging studies}

Imaging included conventional XR (Figure 3), CT (Figure 4) and MRI (Figure 5). All patients had an XR initially, eight went on to have an MRI and three had a CT scan. Of the patients who had an MRI scan $(n=8)$, three had no further imaging while five patients subsequently underwent a CT scan as the result of the MRI was inconclusive but $\mathrm{OO}$ was suspected. $\mathrm{OO}$ was accurately diagnosed in four of these CT scans.

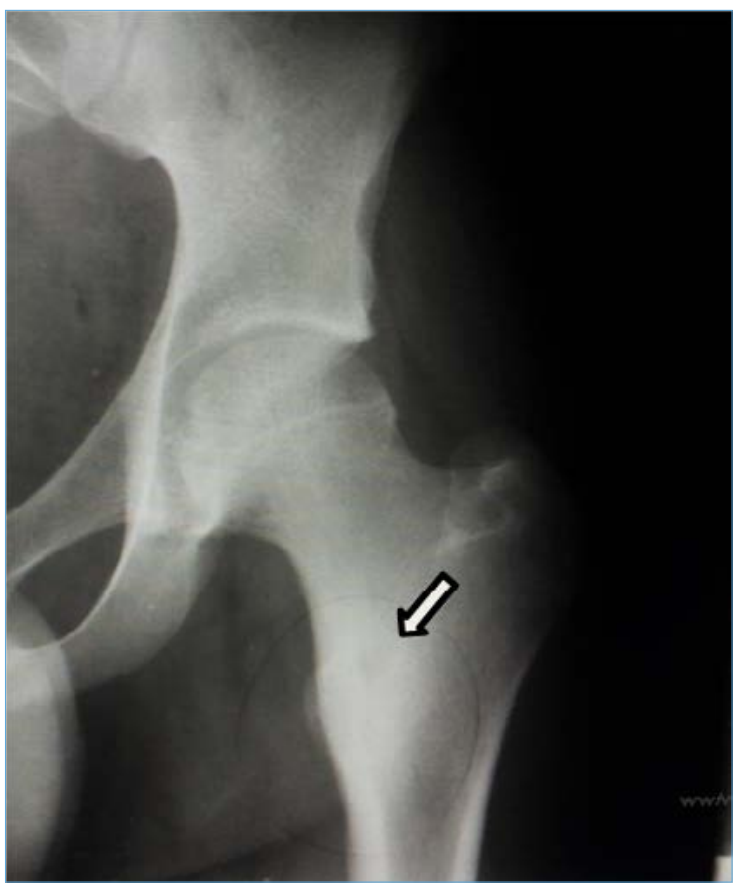

Figure 3. XR of an $\mathrm{OO}$ in the left proximal femur (arrow)

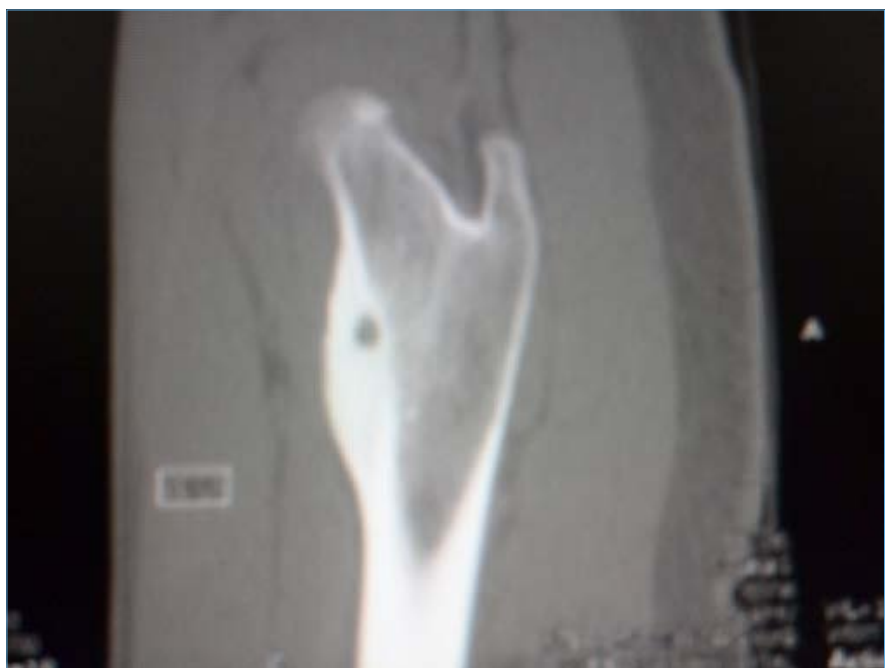

Figure 4. Coronal CT of the left proximal femur; note the clearly defined nidus

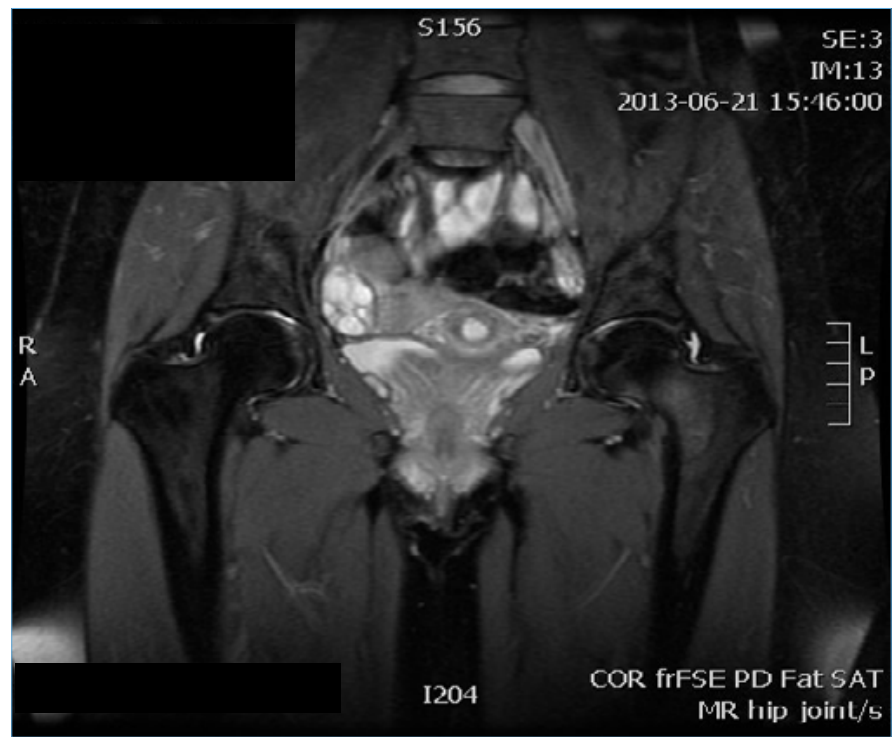

Figure 5. MRI of the same patient as in Figure 1; note the poor differentiation of the nidus and marked surrounding bone oedema (PD fat sat)

\section{Location and histology}

The location of the lesions as well as the initial and final diagnoses are summarised in Table I. No lesion was larger than $20 \mathrm{~mm}$ in diameter, with a median of $9 \mathrm{~mm}$ (range 4-20 mm). Microbial culture was negative in all cases. Nine patients were thought to have an $\mathrm{OO}$ on clinical and radiological assessment pre-operatively. In two of these patients, subacute osteitis was included in the differential diagnosis. Histological examination confirmed $\mathrm{OO}$ in five of these nine patients and subacute osteitis (Brodie's abscess) in one. The other three histological diagnoses were an osteochondral defect of the talus with an associated geode cyst, a benign spindle cell lesion and a benign fibrous histiocytoma.

Two patients had a primary diagnosis that did not include OO. One patient was thought to have a chondroblastoma of the calcaneus that was confirmed on biopsy while the other patient, with a lesion in the ilium adjacent to the sacroiliac joint, had a wider radiological differential diagnosis including osteoblastoma, chondroblastoma or a subchondral geode. Histology proved this to be a benign spindle cell lesion. 
Table I: Summary of patient demographics, lesion location and diagnoses

\begin{tabular}{|c|c|c|c|c|c|c|}
\hline & Age & Sex & Location & $\begin{array}{l}\text { Duration of } \\
\text { symptoms (months) }\end{array}$ & Provisional diagnosis & Histological diagnosis \\
\hline 1 & 19 & Male & Calcaneus & 3 & Chondroblastoma & Chondroblastoma \\
\hline 2 & 20 & Female & Proximal femur & 26 & Osteoid osteoma & Osteoid osteoma \\
\hline 3 & 19 & Male & Proximal tibia & 6 & Osteoid osteoma & Osteoid osteoma \\
\hline 4 & 33 & Female & Talus & 13 & Osteoid osteoma & OCD/geode cyst \\
\hline 5 & 16 & Male & Proximal tibia & 18 & Osteoid osteoma & Osteoid osteoma \\
\hline 6 & 11 & Female & Calcaneus & 3 & Osteoid osteoma & Benign fibrous histiocytoma \\
\hline 7 & 12 & Male & Distal femur & 6 & Osteoid osteoma or subacute osteitis & $\begin{array}{l}\text { Subacute osteitis } \\
\text { (Brodie's abscess) }\end{array}$ \\
\hline 8 & 19 & Female & Proximal femur & 3 & Osteoid osteoma & Osteoid osteoma \\
\hline 9 & 9 & Female & Pelvis & 1 & $\begin{array}{c}\text { Osteoid osteoma, osteoblastoma or } \\
\text { osteitis }\end{array}$ & Benign spindle cell lesion \\
\hline 10 & 25 & Female & Pelvis & 3 & $\begin{array}{c}\text { Osteoblastoma, chondroblastoma or a } \\
\text { subchondral geode cyst }\end{array}$ & Benign spindle cell lesion \\
\hline 11 & 12 & Male & Tibia & 26 & Osteoid osteoma & Osteoid osteoma \\
\hline
\end{tabular}

\section{Outcomes and follow-up}

The median follow-up time was 42 months (range 30-52 months). No patients had recurrence of symptoms, surgical complications or secondary surgical procedures. In the patients who had histologically confirmed $O O(n=5)$, all patients had pain relief following surgery and remained symptom-free with no radiological signs of recurrence, as did five of the six patients with other diagnoses. The patient whose symptoms did not resolve had a diagnosis of an osteochondral lesion of the talus and was referred to a foot and ankle specialist for further treatment.

\section{Discussion}

The aim of this study was to present our experience with CT-guided intralesional curettage of benign bone tumours, with an emphasis on $\mathrm{OO}$.

Localised pain is the most common primary presenting complaint ( $85 \%$ of cases) and is classically described as being worse at night and relieved by NSAIDs. ${ }^{18,19}$ Night pain was present in all of our patients with $\mathrm{OO}$ as well two patients with other tumour diagnoses. Six of the 11 patients reported symptomatic relief with NSAID use. Of these six, three had a final diagnosis of an OO. The natural history of $\mathrm{OO}$ is to resolve over time and up to $40 \%$ of patients experience long-term relief with NSAIDs. ${ }^{20}$ For this reason some authors advocate non-operative management. ${ }^{5}$ All patients in our series had failed a trial of conservative management prior to surgical intervention. As a tertiary referral centre all patients had at least one form of imaging modality prior to referral to our clinic and presented to us with a differential diagnosis of $\mathrm{OO}$ or other small benign lesion.

OO has been described mainly in young patients and is most common in the long bones of the lower limbs, especially in the metaphyseal region of the femur and tibia. ${ }^{18,19}$ We noted similar findings of age and location in our case series, but found that the clinical presentation was neither sensitive nor specific for predicting the diagnosis. Hence, we believe histological confirmation should be an essential part of the surgical management of these lesions.

The time from onset of symptoms to surgical treatment ranged from 1-25 months (median 14 months). This diagnostic delay is not unique to our setting and is due to the rarity of the condition and wide differential for limb pain in the active young patient. Cantwell noted a mean delay to diagnosis of 16 months. ${ }^{21}$ Richardson describes a missed case of intra-articular $\mathrm{OO}$ in the hip of an 18-year-old patient where the diagnostic delay was 2.5 years due to inadequate imaging and failure to suspect the diagnosis. ${ }^{22}$ In our series a young male sportsman with a proximal tibia OO initially presented with knee pain and meniscal symptoms. An MRI failed to diagnose an $\mathrm{OO}$ and the presumed cause of his pain was meniscal pathology. After a failed course of conservative treatment, a repeat $\mathrm{MRI}$ and a CT scan diagnosed an OO that was successfully treated by the method described above. Skeletal imaging plays a major role in the diagnosis of $\mathrm{OO}$. Initially plain X-rays are the modality of choice due to the relatively low cost and radiation exposure, but the diagnostic yield is far superior with CT.23-25 The potential advantage of MRI over CT is in decreased radiation exposure, particularly to the paediatric patient, but the diagnostic accuracy has been shown to be inferior. ${ }^{26,27}$ Hosalkar et al. found MRI only had a 19\% (7/36) accuracy in diagnosing OO, while all lesions in this series were accurately diagnosed pre-operatively on fine cut CT imaging..$^{28}$ The use of gadolinium enhancement in MRI scanning may improve diagnostic accuracy but this increases cost and it has not been shown to be superior to CT. ${ }^{29}$ In our series, CT was more accurate in diagnosing OO; four of the five patients with an $\mathrm{OO}$ had an inconclusive MRI but went on to have a CT that accurately diagnosed $\mathrm{OO}$.

Microbiological culture was negative in all patients, despite one patient having subacute osteitis on histological examination. Negative cultures in subacute osteitis are well described. ${ }^{30}$

\section{The role of surgical management and different techniques}

The most common indication for surgery is failed medical management. ${ }^{17}$ Other indications include prevention of growth deformity in intra-articular or juxta-epiphyseal lesions and the need for histological confirmation of the diagnosis. ${ }^{18}$ While some authors advocate treatment without biopsy, ${ }^{8}$ we believe it is an essential part of management. Surgical options range from open marginal resection to less invasive image-guided techniques such as radiofrequency ablation (RFA), laser photocoagulation and intralesional curettage. These are summarised in Table II.

Marginal resection is associated with prolonged surgical time, local morbidity, fracture in up to $4.5 \%$ of cases, ${ }^{31}$ and a recurrence rate of up to $9 \% .^{32}$ Less invasive procedures are therefore preferred. ${ }^{33}$ Open intralesional excision is less invasive, results in less local morbidity and has a more rapid recovery. $31,32,34$ Intraoperative imaging can be augmented with tetracycline labelling 
Table II: Descriptions of interventional techniques for the treatment of benign lesions of bone

\begin{tabular}{|c|c|c|c|}
\hline Description & Technique & Advantage & Disadvantage \\
\hline $\begin{array}{l}\text { Wide marginal resection } \\
\text { ('en-bloc') }\end{array}$ & $\begin{array}{l}\text { Extensive open surgical procedure; } \\
\text { lesion excised with margin of } \\
\text { normal bone }\end{array}$ & $\begin{array}{l}\text { No additional equipment needed; } \\
\text { technically relatively simple }\end{array}$ & $\begin{array}{l}\text { Large soft tissue dissection; } \\
\text { moderate bone defect; longer } \\
\text { recovery time; fracture risk }{ }^{31,34}\end{array}$ \\
\hline $\begin{array}{l}\text { Open intralesional resection } \\
\text { ('burr-down') }\end{array}$ & $\begin{array}{l}\text { Open procedure; nidus directly } \\
\text { removed without any margin of } \\
\text { bone under image guidance }\end{array}$ & $\begin{array}{l}\text { Less soft tissue dissection and } \\
\text { minimal bone excised }\end{array}$ & $\begin{array}{l}\text { Difficulty in locating lesion may } \\
\text { require the use of adjuncts; } \\
\text { recurrence risk } \\
\text { r1,32,34 }\end{array}$ \\
\hline $\begin{array}{l}\text { Percutaneous CT-guided } \\
\text { intralesional curettage }\end{array}$ & $\begin{array}{l}\text { Guide wire placed under CT; nidus } \\
\text { removed by indirect means under } \\
\text { fluoroscopic guidance }\end{array}$ & $\begin{array}{l}\text { Percutaneous procedure; minimal } \\
\text { soft tissue trauma; low fracture risk; } \\
\text { histology specimen }\end{array}$ & $\begin{array}{l}\text { Requires radiology services to } \\
\text { place guide wire }{ }^{17}\end{array}$ \\
\hline Percutaneous CT-guided RFA & $\begin{array}{l}\text { CT-guided wire placement followed } \\
\text { by RFA; nidus ablated by thermal } \\
\text { necrosis }\end{array}$ & $\begin{array}{l}\text { Percutaneous procedure; minimal } \\
\text { soft tissue trauma }\end{array}$ & $\begin{array}{l}\text { Requires radiology services to } \\
\text { place guide wire; lower histological } \\
\text { yield; additional equipment needed } \\
\text { including RF generator and single } \\
\text { use probes }{ }^{36}\end{array}$ \\
\hline $\begin{array}{l}\text { Percutaneous CT (or MRI)- } \\
\text { guided laser photocoagulation }\end{array}$ & $\begin{array}{l}\text { As for RFA but uses laser to ablate } \\
\text { lesion }\end{array}$ & $\begin{array}{l}\text { Potentially less radiation than RFA } \\
\text { (can be performed under MRI } \\
\text { guidance) }\end{array}$ & $\begin{array}{l}\text { Increased cost with no proven } \\
\text { benefit over RFA }{ }^{9-11}\end{array}$ \\
\hline Arthroscopic excision & $\begin{array}{l}\text { Lesion excised under arthroscopic } \\
\text { visualisation with a burr }\end{array}$ & A minimally invasive technique & $\begin{array}{l}\text { Requires specialised skill and } \\
\text { surgical equipment; only suitable } \\
\text { for intra-articular lesions }{ }^{12-15}\end{array}$ \\
\hline $\begin{array}{l}\text { Magnetic resonance- } \\
\text { guided focused ultrasound }\end{array}$ & $\begin{array}{l}\text { MRI-guided focused US causes } \\
\text { heat necrosis of the lesion }\end{array}$ & $\begin{array}{l}\text { A non-invasive, transcutaneous } \\
\text { technique }\end{array}$ & $\begin{array}{l}\text { Requires specialised equipment, } \\
\text { not readily available in most } \\
\text { centres; as for surgical procedures, } \\
\text { regional or general anaesthesia is } \\
\text { required; no histology }{ }^{38}\end{array}$ \\
\hline
\end{tabular}

and intra-operative scintigraphy to improve accuracy where these technologies are available. ${ }^{19}$ There is no consensus on the benefit of adjuncts (liquid nitrogen, ethanol or PMMA) and there is ample evidence that simply removing the nidus is sufficient to bring about symptomatic relief., ${ }^{1,16}$ The use of CT to accurately localise the nidus allows for a minimally invasive percutaneous surgical approach. ${ }^{23}$ Clinical success is achieved in $84-100 \%$ and importantly, histological yield is reported between 50 and $100 \% .^{17}$ Complications are rare but fracture has been reported with open lesional excision. ${ }^{35}$

RFA is considered by many to represent the gold standard of care. ${ }^{36}$ Two techniques are described: an RFA-only technique and a combined technique, comprising biopsy and RFA. Histological yield ranges from $17-100 \%$ (mean 55\%) with the combined technique as the entire lesion is not available for examination. ${ }^{17}$ Lanzo et al. grouped data from 27 published articles including 1227 patients in an attempt to determine best-practice guidelines for RFA. ${ }^{16}$ They found a $5 \%(61 / 1227)$ primary failure rate and a $2 \%(44 / 1227)$ complication rate. These complications are listed in Table III.

The use of laser photocoagulation to induce thermal necrosis has also been described and can be performed under CT guidance or using MRI. ${ }^{9-11}$ The advantage of MRI is that there is no ionising radiation but it may be more expensive and is not available in all centres. Histological specimens are not usually sent.

Overall the rate of complications and cure for the percutaneous image-guided techniques are very similar. The possible shorter surgical time of drill curettage may result in more cost-effective treatment. Dual technique RF may have equal histological yield and the same cure rates but longer procedural time and possibly higher cost due to the cost of the probes. Thermal ablation alone does not allow for histological confirmation. Our preferred approach is CT-guided excision, as no additional potentially costly equipment is needed, and it can be performed as day case surgery.

Intra-articular $\mathrm{OO}$ may be approached by arthroscopic means and lesions can be excised by curettage or using a high-speed bur. The use of this technique has been described in the hip (both
Table III: List of complications associated with RF ablation $(n=1227)^{16}$

\begin{tabular}{|l|c|}
\hline Primary failure & $61(5 \%)$ \\
\hline Skin burn & 12 \\
\hline Muscle burn & 6 \\
\hline Nerve injury & 3 \\
\hline Fracture & 2 \\
\hline Technical difficulty & 5 \\
\hline Infection & 2 \\
\hline Anaesthetic complication & 3 \\
\hline Delayed healing & 2 \\
\hline
\end{tabular}

femoral and acetabular sided lesions), knee, shoulder, ankle and talus. ${ }^{12-15}$ Proposed advantages are the minimally invasive surgical approach and limited articular injury when compared with RFA and open surgical excision. However, arthroscopic surgery is technically demanding and has a prolonged learning curve.

MRgFUS is a novel treatment of $\mathrm{OO}$ that is currently under investigation. ${ }^{37}$ It is a closed technique and thus avoids some of the complications associated with a surgical procedure but regional or general anaesthesia is still necessary as the procedure is painful. In a series of 29 patients, Geiger and colleagues report a $90 \%$ primary success rate with no adverse events. ${ }^{38}$ Problems include the high cost of the specialised imaging, interventional equipment necessary to perform the procedure, and the lack of a tissue diagnosis.

\section{Cost implications of different treatment modalities}

The cost of health care in both developed and developing economies is increasing at an alarming rate and the importance of cost containment cannot be overemphasised. ${ }^{39}$ Moser et al. found the cost of consumables for Laser photocoagulation and RFA to be equivalent, ${ }^{11}$ while Hoffmann et al. found RFA, which 
was performed as an outpatient procedure, to be the most cost effective with a base price of \$6 583.00 USD (R81 359.00). Open resection $\$ 13826.00$ USD (R170 876.00), intralesional resection $\$ 10857.00$ USD (R13 4182.00) and CT-guided drill curettage $\$ 8589.00$ USD (R106 150.00) were all more expensive. ${ }^{36}$ However these results from Germany cannot be extrapolated to other regions as in different economies certain elements of the treatment package may have different financial weightings. For example, a procedure which takes less theatre time but uses more expensive consumables may be cost effective in one country while being unaffordable in another. Also of note is that the cost of CT, MRI, fluoroscopy, theatre time, anaesthesia, hospital stay, post-operative rehabilitation and time away from work have not been assessed in the above figures and impact on the economic cost to hospital and patient.

Overall, the limitations of the study include the small, heterogeneous sample and the retrospective nature of data gathering. No specific pain or functional scores were used, and no specific statistical tests could be applied to our data. CT scan was not performed post-operatively.

\section{Conclusion}

As novel techniques to deal with small benign bone tumours are becoming ever more popular, the additional time and cost may not be justified by better patient outcomes. In our series we found these elusive lesions difficult to diagnose based purely on clinical and radiological findings. While CT scan is the imaging modality of choice, histological confirmation remains an essential part of surgical management. For the included patients, CT-guided biopsy and intralesional curettage was a safe, effective, minimally invasive treatment option with high histological yield. Future research should focus on cost effectiveness and duration of these procedures compared to conventional techniques. Sufficiently powered multicentre trials are necessary to support recommendations for South African orthopaedic surgeons treating these lesions.

\section{Ethics statement}

Ethics approval was obtained from the University of Cape Town Human Research Ethics Committee (Ethics number HREC REF: 670/2016). Patient information was obtained from a prospective database at Groote Schuur and Vincent Pallotti Hospitals. The Ethics Committee approved these databases, and their reference numbers respectively are R039/2013 and R001/2015. For this study formal consent was not required.

\section{Declaration}

The authors declare authorship of this article and that they have followed sound scientific research practice. This research is original and does not transgress plagiarism policies.

\section{Author contributions}

$\mathrm{KH}$ conceived of the research idea and was the primary surgeon in all cases. TH assisted with application to the departmental research committee and ethics board. $\mathrm{TH}$ and TSC developed the study protocol and gathered patient data. TSC, TH and $\mathrm{MH}$ contributed to writing up the manuscript for submission.

\section{ORCID}

Sluis Cremer T (D) https://orcid.org/0000-0003-1491-0534

Hosking K (D) http://orcid.org/0000-0002-3557-0252

Held M ID https://orcid.org/0000-0002-0671-0439

Hilton TL (D) https://orcid.org/0000-0002-6178-5062

\section{References}

1. Kransdorf MJ, Stull M, Gilkey F, Moser Jr R. Osteoid osteoma. Radiographics. 1991;11(4):671-96.

2. Greenspan A, Jundt G, Remagen W. Differential diagnosis in orthopaedic oncology: Lippincott Williams \& Wilkins; 2007.
3. Kneisl J, Simon M. Medical management compared with operative treatment for osteoid-osteoma. J Bone Joint Surg Am. 1992;74(2):179-85.

4. Moberg E. The natural course of osteoid osteoma. JBJS. 1951;33(1):166-70.

5. Feletar M, Hall S. Osteoid osteoma: A case for conservative management. Rheumatology. 2002;41(5):585-6.

6. Yokouchi M, Nagano S, Shimada H, Nakamura S, Setoguchi T, Kawamura I, et al. Early complete remission of osteoid osteoma with conservative medical management. Pediatric reports. 2014;6(1).

7. Atesok KI, Alman BA, Schemitsch EH, Peyser A, Mankin H. Osteoid osteoma and osteoblastoma. Journal of the American Academy of Orthopaedic Surgeons. 2011;19(11):678-89.

8. Ghanem I. The management of osteoid osteoma: Updates and controversies. Current opinion in pediatrics. 2006;18(1):36-41.

9. Gangi A, Alizadeh H, Wong L, Buy X, Dietemann J-L, Roy C. Osteoid osteoma: Percutaneous laser ablation and follow-up in 114 patients 1. Radiology. 2007;242(1):293-301.

10. Gangi A, Dietemann J-L, Gasser B, Mortazavi R, Brunner P, Mourou MY, et al. Interstitial laser photocoagulation of osteoid osteomas with use of ct guidance. Radiology. 1997;203(3):843-48.

11. Moser T, Giacomelli M-C, Clavert J-M, Buy X, Dietemann J-L, Gangi A. Image-guided laser ablation of osteoid osteoma in pediatric patients. Journal of Pediatric Orthopaedics. 2008;28(2):265-70.

12. Denker JA, Fritts HM, Stone RM, Larson CM. Hip arthroscopy for removal of an acetabular rim-based osteoid osteoma and concomitant femoroacetabular impingement correction. Arthroscopy techniques. 2016;5(6):e1215-e20.

13. Yercan HS, Okcu G, Özalp T, Ösiç U. Arthroscopic removal of the osteoid osteoma on the neck of the talus. Knee Surgery, Sports Traumatology, Arthroscopy. 2004;12(3):246-49.

14. Adachi N, Shimose S, Nakamae A, Okuhara A, Kamei G, Ochi M. Intra-articular osteoid osteoma of the lateral tibial plateau treated with arthroscopically assisted removal and retrograde osteochondral grafting. The Knee. 2014;21(1):343-48.

15. Ueyama H, Ito $\mathrm{Y}$, Manaka T, Matsumoto I, Ichikawa K, Nakamura H. Arthroscopic treatment of an osteoid osteoma at the base of the coracoid process: A case report. Journal of Orthopaedic Science. 2016;21(2):245-49.

16. Lanza E, Thouvenin Y, Viala P, Sconfienza LM, Poretti D, Cornalba $\mathrm{G}$, et al. Osteoid osteoma treated by percutaneous thermal ablation: When do we fail? A systematic review and guidelines for future reporting. Cardiovascular and interventional radiology. 2013:1-10.

17. Reverte-Vinaixa MM, Velez $R$, Alvarez $S$, Rivas $A$, Perez $M$ Percutaneous computed tomography-guided resection of non-spinal osteoid osteomas in 54 patients and review of the literature. Archives of orthopaedic and trauma surgery. 2013;133(4):449-55.

18. Yildiz Y, Bayrakci K, Altay M, Saglik Y. Osteoid osteoma: The results of surgical treatment. International orthopaedics. 2001;25(2):119-22.

19. Greenspan A. Benign bone-forming lesions: Osteoma, osteoid osteoma, and osteoblastoma. Skeletal radiology. 1993;22(7):485-500.

20. Kitsoulis P, Mantellos G, Vlychou M. Osteoid osteoma. Acta orthopaedica Belgica. 2006;72(2):119.

21. Cantwell CP, Obyrne J, Eustace S. Current trends in treatment of osteoid osteoma with an emphasis on radiofrequency ablation. Eur Radiol. 2004;14(4):607-17.

22. Richardson MD, Taylor JAM. Intra-articular osteoid osteoma in the femoral neck of an 18-year-old man: A case report. Journal of Manipulative and Physiological Therapeutics. 2009;32(3):245-50.

23. Fenichel I, Garniack A, Morag B, Palti R, Salai M. Percutaneous ct-guided curettage of osteoid osteoma with histological confirmation: A retrospective study and review of the literature. International orthopaedics. 2006;30(2):139-42.

24. Voto SJ, Cook AJ, Weiner DS, Ewing JW, Arrington EL. Treatment of osteoid osteoma by computed tomography guided excision in the pediatric patient. Journal of Pediatric Orthopaedics. 1990;10(4):510-13. 
25. Bühler M, Exner GU, Hodler J. CT-assisted percutaneous removal of an osteoid osteoma. Orthopedics and Traumatology. 2001;9(3):159-65.

26. Baunin C, Puget C, Assoun J, Railhac J, Cahuzac J, Clement J, et al. Percutaneous resection of osteoid osteoma under ct guidance in eight children. Pediatric radiology. 1994;24(3):185-88.

27. Scalici J, Jacquel A, Mukish P, Trouilloud P, Baulot E. Intra-articular osteoid osteoma of the hip misdiagnosed by mri: An unusual cause of unexplained hip pain. Orthopaedics \& Traumatology: Surgery \& Research. 2011;97(8):881-85.

28. Hosalkar HS, Garg S, Moroz L, Pollock A, Dormans JP. The diagnostic accuracy of MRI versus CT imaging for osteoid osteoma in children. Clinical orthopaedics and related research. 2005;433:171-77.

29. Von Kalle T, Langendörfer M, Fernandez F, Winkler P. Combined dynamic contrast-enhancement and serial 3d-subtraction analysis in magnetic resonance imaging of osteoid osteomas. Eur Radiol. 2009;19(10):2508-17.

30. Willis R, Rozencwaig R. Pediatric osteomyelitis masquerading as skeletal neoplasia. The Orthopedic clinics of North America. 1996;27(3):625-34.

31. Sluga $M$, Windhager R, Pfeiffer M, Dominkus M, Kotz R. Peripheral osteoid osteoma. JBJS 2002;84(2):249-51.

32. Rosenthal DI, Hornicek FJ, Wolfe MW, Jennings LC, Gebhardt MC Mankin HJ. Percutaneous radiofrequency coagulation of osteoid osteoma compared with operative treatment. The Journal of Bone \& Joint Surgery. 1998;80(6):815-21.

33. Lee EH, Shafi M, Hui JH. Osteoid osteoma: A current review. Journal of Pediatric Orthopaedics. 2006;26(5):695-700.

34. Ward WG, Eckardt JJ, Shayestehfar S, Mirra J, Grogan T, Oppenheim W. Osteoid osteoma diagnosis and management with low morbidity. Clinical Orthopaedics and related research. 1993;291:229-35.

35. Sans N, Galy-Fourcade D, Assoun J, Jarlaud T, Chiavassa H, Bonnevialle $\mathrm{P}$, et al. Osteoid osteoma: Ct-guided percutaneous resection and follow-up in 38 patients 1. Radiology. 1999;212(3):687-92.

36. Hoffmann R-T, Jakobs TF, Kubisch $\mathrm{CH}$, Trumm CG, Weber C, Duerr H-R, et al. Radiofrequency ablation in the treatment of osteoid osteoma-5-year experience. European Journal of Radiology. 2010;73(2):374-79.

37. Masciocchi C, Zugaro L, Arrigoni F, Gravina GL, Mariani S, La Marra $A$, et al. Radiofrequency ablation versus magnetic resonance guided focused ultrasound surgery for minimally invasive treatment of osteoid osteoma: A propensity score matching study. Eur Radiol. 2016;26(8):2472-81.

38. Geiger D, Napoli A, Conchiglia A, Gregori LM, Arrigoni F, Bazzocchi A, Busacca M, Moreschini O, Mastantuono M Albisinni U, Masciocchi C. MR-guided focused ultrasound (MRgFUS) ablation for the treatment of nonspinal osteoid osteoma: a prospective multicenter evaluation. JBJS. 2014 May 7;96(9):743-51.

39. Edejer TT-T. Making choices in health: WHO guide to cost-effectiveness analysis: World Health Organization; 2003. 